RELATO DE EXPERIÊNCIA

\title{
O ensino das práticas de aventura e a contextualização da determinação social da saúde
}

The teaching of adventure practices and the contextualization of the social determination of health

\author{
Regina Queiroz Silva ${ }^{1}$, Leonardo Carlos de Andrade², Isaac Neves de Lima ${ }^{3}$, Katiane dos Santos Costa ${ }^{3}$ \\ ${ }^{1}$ Universidade Estadual de Goiás (UEG), Goiânia, Brasil \\ ${ }^{2}$ Instituto Federal Goiano (IFG), Goiânia, Brasil \\ ${ }^{3}$ Universidade Federal de Goiás (UFG), Goiânia, Brasil
}

\author{
HISTÓRICO DO ARTIGO \\ Recebido: 27 maio 2021 \\ Revisado: 01 julho 2021 \\ Aprovado: 07 julho 2021
}

\section{PALAVRAS-CHAVE:}

Educação física; Práticas corporais de aventura; Saúde coletiva; Escola.

\section{KEYWORDS:}

Physical education; Practical body adventure; Collective health; School.

\section{RESUMO}

INTRODUÇÃO: Este artigo expõe uma sequência didática com o conteúdo práticas corporais de aventura, tomando como principal enfoque as articulações com o debate sobre saúde coletiva a partir da pedagogia histórico-crítica e dos princípios curriculares para o trato com o conhecimento da abordagem crítico-superadora. Compreendendo que a saúde coletiva está pautada em um aporte dialético e que toma a totalidade do indivíduo nessa particularidade histórica, defendemos que essa concepção de saúde tem envergadura suficiente para dialogar com o ensino das diferentes atividades da Cultura Corporal na busca por uma formação crítica. OBJETIVO: O objetivo é apresentar o caminho teórico-metodológico do ensino das práticas corporais de aventura considerando as possibilidades de usufruto e vivência em meio urbano, mais especificamente nos parques da cidade de Goiânia.

MÉTODOS: A metodologia de exposição foi delineada a partir dos princípios de um relato de experiência, que visa apresentar detalhadamente uma proposta pedagógica já materializada em diálogo com a produção científica. Concomitantemente foi desenvolvido um debate acerca da saúde coletiva apresentando as determinações sociais do trabalho e as contradições dessa sociedade onde os trabalhadores não têm acesso à cultura corporal e ao tempo de lazer, impactando sua saúde.

RESULTADOS: a) o processo de ensino e aprendizagem das práticas corporais de aventura na terra, no ar e na água, em suas modalidades arvorismo, slackline e stand up paddle e dimensões técnicas, históricas e de vertigem; b) Debate sobre as formas de acesso às práticas de aventura e exploração dos espaços públicos em Goiânia; c) Compreender as contradições acerca da particularidade de nossa sociedade (capitalismo); d) Construção de material alternativo.

CONCLUSÃO: Os alunos compreenderam os conceitos das práticas corporais de aventura e os determinantes sociais da saúde, tecendo críticas à falta de políticas públicas de acesso à cultura corporal e apontando possibilidades alternativas (e provisórias) para a comunidade vivenciar e usufruir destes bens, mesmo à contragosto da lógica do capital.

\section{ABSTRACT}

BACKGROUND: This article presents a didactic sequence with the content of corporal practices of adventure, taking as main focus the articulations with the debate on collective health from the historical pedagogy-critical and curricular principles for dealing with the knowledge of the critical-overcoming approach. Understanding that collective health is based on a dialectical contribution and that it takes the whole of the individual in this historical particularity, we defend that this concept of health has sufficient scope to dialogue with the teaching of the different activities of Body Culture in the search for a critical training.

OBJECTIVE: The objective is to present the theoretical-methodological path of the teaching of the corporal practices of adventure considering the possibilities of enjoyment and living in urban environment, more specifically in the parks of the city of Goiânia, GO, Brazil.

METHODS: The methodology of exposition was outlined based on the principles of an experience report, which aims to present in detail a pedagogical proposal already materialized in dialogue with the scientific production. RESULTS: a) the process of teaching and learning the corporal practices of adventure on land, in the air and in the water, in their modalities tree climbing, slackline and stand up paddle and technical, historical and vertigo dimensions; b) Debate on the forms of access to the practices of adventure and exploration of public spaces in Goiânia; c) Understanding the contradictions about the particularity of our society (capitalism); d) Construction of alternative material.

CONCLUSION: The students understood the concepts of the corporal practices of adventure and the social determinants of health, criticizing the lack of public policies of access to body culture and pointing out alternative (and provisional) possibilities for the community to experience and enjoy these goods, even against the logic of capital. 


\section{INTRODUÇÃO}

O artigo se caracteriza como um relato de experiência, trazendo à tona uma proposta desenvolvida em uma unidade de ensino particular, localizada no município de Goiânia, com uma turma do 70 ano do Ensino Fundamental formada por 23 alunos. O objetivo central deste artigo é relatar o processo de ensino das práticas corporais de aventura em articulação com o debate sobre saúde coletiva. O caminho didático-pedagógico que é objeto deste artigo parte da compreensão de que as práticas corporais de aventura constituem o acervo de formas e atividades da cultura corporal, sabendo que esta é histórica e dialética.

Escobar e Taffarel (2009) evidenciam que não há linearidade ou finitude nas atividades da cultura corporal. Se o jogo, a dança, as lutas, a ginástica e os esportes são produções humanas criadas e desenvolvidas ao longo da história pelo trabalho a fim de satisfazer necessidades humanas, as práticas corporais de aventura emergiram como expressões da atividade humana, que hoje também constituem a cultura corporal. Andrade (2020) salienta que a própria Base Nacional Comum Curricular (BNCC) apresenta as práticas corporais de aventura como conteúdo da Educação Física, apesar do documento possuir limitações teóricas pelo simplismo que trata as disciplinas escolares e concepções endógenas de desenvolvimento humano, muito influenciada pelas pedagogias do aprender a aprender.

Ao contrário da BNCC e em concordância com Escobar e Taffarel (2009) e Andrade (2020) este artigo possui uma compreensão materialista e dialética da história. Entende-se que a saúde coletiva tem envergadura e coerência para o debate crítico de saúde na escola. Carvalho (2005, p. 20) define a saúde coletiva como sendo "[...] um campo de saberes e práticas que toma como objeto as necessidades sociais de saúde, com o intuito de construir possibilidades interpretativas e explicativas dos fenômenos" para além da relação saúde-doença, superando a concepção formal e unilateral de ser humano pelo pensamento por contradições.

Advoga-se que a articulação entre a cultura corporal e a saúde coletiva é possível pela seguinte intermediação: se para Taffarel (2016) a Cultura Corporal possui, de modo coagulado, as dimensões políticas, históricas, motrizes, estéticas, agonísticas, lúdicas e de saúde, Bonfim et al. (2013) compreendem que a saúde coletiva traz um salto qualitativo na concepção hegemônica de saúde e rompe com o ideário epistemológico inveterado na Educação Física, que compreende o ser humano de forma unidimensional. Isso possibilita o debate de uma destas dimensões (a saúde no caso) em unidade com as demais. A articulação do conteúdo em suas múltiplas determinações é base para se pensar um processo pedagógico concreto (SAVIANI, 2019).

Quanto à seleção dos conteúdos e a forma de abordagem, buscou-se instigar os alunos a pensar sobre a realidade concreta, saindo do papel de passividade, e propôs-se uma ação crítica e deliberada. Libâneo (1985, p. 39), diz que "[...] os conteúdos são realidades exteriores ao aluno que devem ser assimilados e não simplesmente reinventados, eles não são fechados e refratários às realidades sociais", pois "[...] não basta que os conteúdos sejam apenas ensinados, ainda que bem ensinados é preciso que se liguem de forma indissociável a sua significação humana e social". Em outras palavras, para que se cumpra a relevância social do conteúdo selecionado deve-se tomar a reali- dade contraditória em que estamos inseridos.

Desse modo, este artigo se configura como um relato de experiência, com caráter qualitativo-descritivo, o qual, para Severino (2012), é uma modalidade de escrita acadêmica que se propõe a descrever uma atividade ou um campo de forma esmiuçada e embasada teoricamente. Aproveitando tal enredo metodológico, é imposta a justificativa legitimada em três vieses: a) a necessidade emergente de se pensar a Educação Física e seus vários campos, partindo de múltiplas determinações, das quais a saúde coletiva tem grande potencial para contemplar (BONFIM, 2012); b) explorar o conteúdo práticas corporais de aventura, pouco desenvolvido na Educação Física escolar, mostrando a complexificação e riqueza das manifestações da cultura corporal (ANDRADE, 2020); c) expor a realidade da prática pedagógica em seu percurso metodológico e nexos com os fundamentos da educação e da Educação Física cumpre um papel de mostrar a dialética entre singular (chão da escola) e universal (fundamentos pedagógicos histórico-críticos).

Reiteramos que este relato tem como objetivo apresentar o processo de ensino das práticas corporais de aventura para uma turma de Ensino Fundamental em articulação com o debate sobre saúde coletiva. Como método de exposição de um longo processo pedagógico, contempla-se a proposição orientada por meio dos tópicos adiante e na seguinte ordem: aspectos metodológicos do trabalho pedagógico e descrição do processo pedagógico; síntese das articulações entre cultura corporal, Educação Física escolar e saúde coletiva.

\section{MÉTODOS}

O relato de experiência se consolida como uma modalidade específica de produção científica que se difere de uma pesquisa-ação e de uma pesquisa empírica, pois visa apresentar detalhadamente processos pedagógicos ou experiências materializadas em diálogo com a produção científica do campo (FERREIRA; SILVA, 2019). Ao analisarmos os relatos de experiência de Souza et al. (2019) e Bagni et al. (2019) verificamos que um relato de experiência exige no mínimo a exposição metodológica de 5 elementos: a) Lócus de desenvolvimento; b) Sujeitos envolvidos nos processos (Alunos e Professores); c) Duração do projeto ou processo pedagógico; d) descrição do caminho metodológico; e) Fundamentação teórica com os estudos do campo.

Seguindo a metodologia específica de um relato de experiência este artigo apresenta uma experiência realizada nas aulas de educação física de uma escola particular do município de Goiânia (GO), durante o ano de 2020. As aulas tinham periodicidade semanal (uma aula por semana) com a turma de 7 응 ano do ensino fundamental, contendo 23 alunos entre 12 e 13 anos de idade. A responsável pelo desenvolvimento do trabalho pedagógico foi uma professora de Educação Física, docente das turmas do Ensino Fundamental II. Além da unidade de ensino básico da rede particular de Goiânia, os professores também recorreram a praças públicas das regiões sul e oeste da cidade.

O trabalho pedagógico foi desenvolvido ao longo de dois meses (bimestre), sendo que o planejamento foi pautado na tríade conteúdo-forma-destinatário, sendo o conteúdo as práticas corporais de aventura, o destinatário as turmas de 7으 ano e as formas delineadas por uma sequência pedagógica (ANDRADE, 2020). A sequência de desenvolvimento da prática pedagógica 
se deu por meio das seguintes fases: a) apresentação e exploração do conteúdo práticas corporais de aventura na escola; b) exploração do conteúdo práticas corporais de aventura em praças e parques de Goiânia, concomitantemente às problematizações à luz da saúde coletiva; c) confecção de materiais alternativos para vivenciar as práticas corporais de aventura e a viabilização deste acesso à comunidade.

A avaliação do processo pedagógico se deu por 3 instrumentos: 1) Relatório das aulas onde a professora responsável analisou a participação, envolvimento e comentários das turmas durante o bimestre; 2) Questionário sobre os principais conceitos acerca das práticas corporais de aventura e saúde coletiva no final do bimestre; 3) Apresentação oral para as famílias e comunidade escolar, onde os alunos sintetizaram suas experiências em comunicações orais por grupo.

A apresentação e exploração do conteúdo para a turma se deu a partir das possibilidades arquitetônicas de vivenciar as práticas corporais de aventura dentro da escola em conjunto com uma decisão coletiva acerca das modalidades de práticas corporais após levantamento inicial com os alunos mediante a intencionalidade pedagógica do professor em seu planejamento.

\section{RESULTADOS E DISCUSSÃO}

No levantamento inicial do estudo foram consideradas as práticas corporais de aventuras e suas possibilidades de exploração. As práticas corporais de aventura são relacionadas aos movimentos que os primórdios já utilizavam com o objetivo de sobrevivência, entre elas a caça, a pesca e a escalada em árvores (MOURA, 2018). Pensando em compreender essas práticas na atualidade, foram localizadas várias atividades realizadas na terra, no ar e na água, tais como: arvorismo, slackline e stand up paddle. Ao se levar esses conteúdos para o ambiente escolar, quebra-se uma barreira entre os conhecimentos da escola e os conhecimentos fora dos muros do ambiente escolar.

Refletindo sobre a Educação Física à luz do conceito da cultura corporal, que dá sentido e significado aos conteúdos, e abrangendo a compreensão de assuntos como ecologia, saúde pública e distribuição de renda, entre outros, ilustra-se a importância do diálogo entre as práticas do ensino com as condições e necessidades do trato social e suas implicações.

As práticas corporais de aventura e sua íntima relação com a natureza incitam uma série de possibilidades para além da dimensão terapêutica e biologista da área, pois o praticante, ao mesmo tempo em que realiza uma atividade física, supera limites pessoais, relaciona-se com os pares, usufrui de seu momento de ócio, foge da lógica meritocrática de competição e tem, ainda, a possibilidade de alcançar se enriquecer por essa objetivação humano-genérica.

\section{Aproximações entre a educação física escolar e a saúde coletiva}

Nos últimos anos a Educação Física tem se aproximado da saúde coletiva, na busca por um referencial concreto e dialético para se compreender a saúde nesta particularidade histórica.

Entre todos os problemas relacionados à formação em saúde e as aproximações da Educação Física, alguns ainda não foram superados, pois "[...] persiste uma formação inadequada dos profissionais que atuam ou irão atuar no sistema" (MACHADO; VIEI-RA; OLIVEIRA, 2015). Além disso, Campos, Aguiar e Belisário (2008) consideram que:

\section{[...] a defasagem entre "ensino e realidade e aspectos pedagógi-

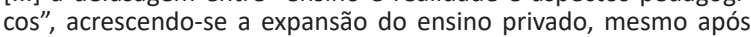 quase 30 anos de SUS, ainda perduram em dificuldades para o desenvolvimento de práticas integrais, de prevenção de riscos, agravos e doenças e de promoção da saúde, seja no cuidado, na as- sistência e na atenção à saúde, às famílias e comunidades nos dife- rentes espaços do território brasileiro. Portanto, faz-se mister uma competente educação na saúde, como diretriz para a qualidade do cuidado, devendo esta ser pautada com base nos determinantes sociais da saúde, nas necessidades da população e de grupos vul- neráveis, no perfil epidemiológico locorregional e com vivências teórico-práticas voltadas para a realidade local (p. 19).}

Nesse contexto, tem-se a saúde coletiva como campo interdisciplinar de conhecimento e âmbito da própria prática, que es-tuda o fenômeno saúde/doença enquanto fenômeno social e que se propõe ao resgate social (PAIM; ALMEIDA FILHO, 1998). $O$ debate sobre saúde coletiva nesse momento se faz necessário, visto que vivemos uma crise sanitária, política, estrutural e socio-ambiental e a discussão sobre sustentabilidade, meio ambiente e relação homem-natureza estão intimamente ligadas às práticas corporais de aventura. Tal debate dá abertura para o olhar sensível à discussão do ser humano perante as relações e os impactos mundiais em múltiplas mediações.

Tendo em vista que somos marcados por uma sociedade contraditória, Andrade (2020) expõe a condição intrínseca ao capita-lismo de que os problemas de caráter social, econômico e político não podem ser superados nesta particularidade história, mas carecem de ser compreendidos e confrontados em sua totalidade. Assim, as possibilidades atreladas ao papel do professor de desvelar a realidade pelo ensino, ampliando a visão dos indivíduos sobre práticas corporais de aventura e saúde, no âmbito da saúde coletiva, é fundamental para se pensar o vir a ser da humanidade.

\section{A experiência na escola: É hora da aventura!}

As práticas corporais de aventura em ambiente escolar foram socializadas durante as aulas de educação física sob a orienta-ção da professora responsável pelo conteúdo. Durante experiência as crianças puderam conhecer as características essenciais das práticas corporais de aventura - o risco controlado, a vertigem, a resiliência e a superação - que de acordo com Andrade (2020) podem ocorrer na terra, na água e no ar. A partir destes conceitos as crianças do grupo selecionado experimentaram algumas modalidades feitas na terra, como a falsa baiana, a travessia macaco e o slackline.

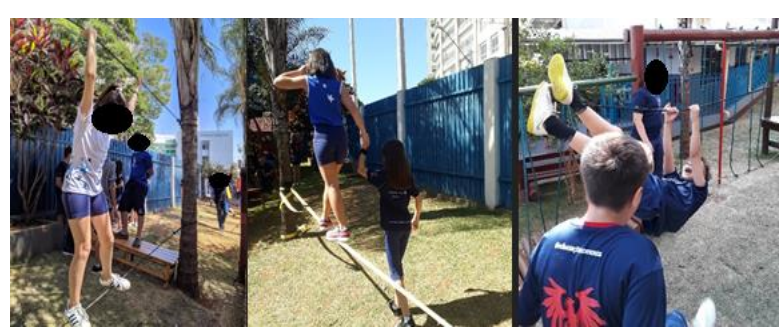

Figura 1. Falsa baiana, a travessia macaco e o slackline. Fonte: Acervo pessoal. 
Para dar início às vivências foram apresentados, aos alunos, vídeos de práticas corporais de aventuras abordando as técnicas de travessia utilizadas em salvamentos e treinamentos militares. A partir da compreensão de finalidade social e do surgimento dessas modalidades (como produção humana que satisfaz necessidades), foi vivenciada a falsa baiana - atividade com duas cordas com, aproximadamente, 1,5 m de distância entre uma e outra para que a pessoa utilize as mãos e os pés na travessia.

Posteriormente vivenciaram o slackline, mais popular entre os alunos, que já conheciam a modalidade por meio das mídias digitais. O movimento Travessia Macaco foi apresentado através da modalidade rope crossing, onde o objetivo é a transposição de um lado para outro se arrastando em uma corda, com um movimento semelhante a um macaco, onde são usados tanto membros inferiores quanto superiores para o deslocamento.

Após vivências com a falsa baiana e o slackline e exposições sobre as práticas corporais de aventura, foi inserida uma problematização intencional para que os alunos refletissem com os questionamentos: Todos vocês já conheciam essas práticas? Se esse conteúdo é desenvolvido predominantemente ao ar livre, por que não vemos isso ocorrer nas praças de Goiânia? Será que as pessoas conhecem? Se não conhecerem não saberão explorar? Será que tem tempo livre para isso? Será que o acesso à cultura e ao lazer tem relação com a saúde? O que é saúde? Que relação tem entre saúde e tempo de trabalho?

A partir das questões foi apresentado um determinante social da saúde: o trabalho. Este foi o marco para afirmar que, na saúde coletiva, o indivíduo, para estar em um processo de vida saudável, deve ter boa alimentação, condição de moradia, de carga de trabalho, acesso à cultura, ao lazer e bom funcionamento do organismo (unidade social-biológica).

Ainda na fase de inicial do processo didático, ocorreu uma aproximação entre diferentes disciplinas, sendo estabelecido um diálogo entre Educação Física, Biologia e Língua Portuguesa. Os professores buscaram nexos entre seus objetos de ensino e a saúde coletiva; no caso da Educação Física por meio das práticas corporais de aventura; no da Biologia pelo funcionamento do organismo e a ontogênese. Do ensino deste tema emergiu um projeto interdisciplinar abrangendo o debate sobre saúde coletiva e práticas de aventura, onde a disciplina de língua portuguesa ficou responsável pela sistematização de um projeto de pesquisa com este tema.

A professora de Gramática dividiu a turma em grupos para realizar a pesquisa com o tema 'Práticas corporais de aventura e a falta de praticantes em Goiânia'. Cada grupo escolheu subtemas para fazer as pesquisas e, em seguida, elaborar um projeto para execução e apresentação para a escola e para os pais. Assim, após conhecer os principais elementos constituintes do conteúdo e o debate inicial sobre saúde coletiva, os alunos foram levados à campo para vivenciar as práticas de aventura e reconhecer seu direito de usufruir dos espaços públicos, agora munidos de conhecimento suficiente para explorar outras formas.

$\mathrm{Na}$ aula campo foi proposto um encontro extra para uma visitação ao Parque Areião. A visita ao parque serviu como gatiIho para que os participantes do processo, os alunos da unidade de ensino, pudessem entender as possibilidades das práticas de aventura na cidade e as contradições entre o acesso e o não acesso. Vislumbrou-se esta intervenção como possibilidade pro- lífica para o debate da saúde coletiva, tomando o ensino deste conteúdo como

[...] uma estratégia de produção de saúde, ou seja, um modo de pensar e de operar, articulando as demais políticas e tecnologias desenvolvidas no sistema de saúde brasileiro. O papel da educação na promoção da saúde é de fortalecer a ação individual e coletiva com vistas ao empoderamento e à promoção da autonomia da comunidade, além do desenvolvimento de habilidades individuais de modo a contribuir para que sua participação na sociedade seja efetiva (SCABAR; PELICIONE; PELICIONE, 2012, p. 413).

Nesse contexto, utilizou-se de ferramentas tecnológicas e das mídias para o ensino das práticas através de vídeos e pesquisas sobre as relações com o meio ambiente. Mais uma vez emana a saúde coletiva como possibilidade de articulação, pois a partir dela foram problematizadas diferentes formas e motivações de exploração dos espaços públicos. Neste viés, o acesso à essas práticas é uma necessidade também de saúde (enquanto determinante cultural/social), defende-se que, como fatores essenciais para contribuição às necessidades sociais de saúde da comunidade, são necessárias ações públicas para além de ações pontuais como estas.

Nesta ação pedagógica problematizou-se, com os estudantes, diferentes formas de acesso às práticas de aventura e exploração dos espaços públicos de 'lazer', todavia, acredita-se que, através de profissionais da rede Atenção Básica, seria possível um projeto contínuo e deliberado para garantir essa formação e acesso a toda a comunidade. A compreensão de saúde coletiva socializada com os alunos objetivou superar a perspectiva individualizante e fragmentária.

A busca com o processo de ensino aplicado era propor ações de exploração/vivência nos espaços e, ao mesmo tempo, apontar a contradição acerca da forma como normalmente se aborda o modo de viver e de se apropriar destes bens nessa particularidade de nossa sociedade (capitalismo), colocando os sujeitos e a comunidade como responsáveis únicos pelas variáveis mudanças que ocorrem no processo saúde-doença (PAIM; ALMEIDA FILHO, 1998).

A aula de campo, no Parque Areião, foi realizada sob a supervisão do professor de Ciências e da professora de Educação Física, os participantes do processo observaram o parque e as atividades que ali aconteciam e fizeram a coleta de material reciclável a pedido da professora. Conforme dito, os alunos, instrumentalizados pelo conhecimento acerca das modalidades de práticas de aventura, puderam explorar o parque de outras formas e com distintas intencionalidades.

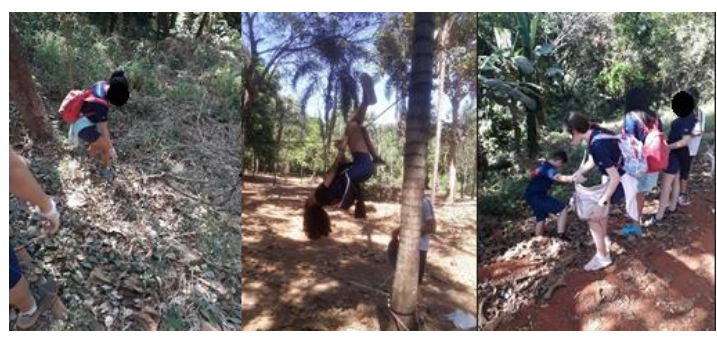

Figura 2. Vivências e exploração no Parque Areião (GO). Fonte: Acervo pessoal.

Os materiais recicláveis requeridos pela professora e recoIhidos pelos alunos serviram para a terceira fase do processo 
didático, uma proposição de intervenção nos parques e oportunidade para a comunidade. Portanto, nessa etapa os alunos reuniram garrafas pet e pneus usados para a construção de equipamentos alternativos de práticas de aventura que poderiam oportunizar o acesso à comunidade e o conhecimento da existência destas atividades da cultura corporal.

Os professores orientaram os alunos para uma confecção de prancha de stand up paddle. Esse processo pode ser replicado em outras escolas pelo Brasil, basta, aproximadamente, 100 garrafas pet do mesmo modelo, cola de PU expansiva, cano de PVC $25 \mathrm{~mm}$, E.V.A. e gelo seco. Dessas garrafas, 50 deverão ficar inteiras e com uma pedra pequena de gelo seco dentro, para elas ficarem bem cheias. As demais garrafas deverão ser cortadas nas partes de cima e demais para ficar com o formato de um cano. Em seguida faz-se a colagem das garrafas, formando cinco tubos grandes, com, aproximadamente, seis garrafas cheias e seis garrafas cortadas. Depois de todo o processo as garrafas devem serem alinhadas para ficarem retas e organizadas. Após a secagem, de um dia para o outro, começa-se a montagem, ligando os grandes tubos uns aos outros, sendo que os espaços entre eles devem ser colados os PVCs e as E.V.As. A colagem segue o padrão de uma prancha. É necessário fazem umas quilhas, para as quais se pode utilizar CDs.

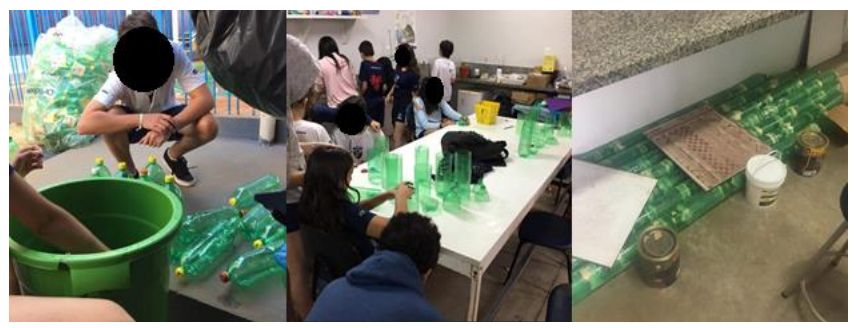

Figura 3. Construção da prancha de standup padle. Fonte: Acervo pessoal.

A partir do recolhimento de pneus usados foi construída uma parede de escalada, segura e resistente que poderia ser implementada em qualquer praça pública pelas entidades responsáveis. Para a construção da parede de escalada foram utilizados pneus de moto e cordas, sendo que os pneus foram amarrados uns aos outros, formando uma parede; depois os pneus foram presos em uma estrutura pronta no parque da escola. A exploração da parede de escalada e o processo de ensino se deu por meio de técnicas de canionismo e escalada.

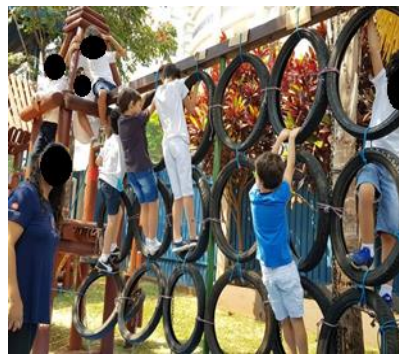

Figura 4. Parede de escalada. Fonte: Acervo pessoal.
Ao final da confecção dos materiais, os alunos vivenciaram o stand up padle e a escalada, conhecendo suas dimensões técnicas, históricas e de vertigem dentro da unidade escolar. Após a fase de experienciação do material confeccionado os alunos apresentaram, no auditório da instituição, para os pais e comunidade escolar, todo o caminho percorrido, com ênfase no seguinte processo: a) as práticas corporais de aventura fazem parte do patrimônio cultural da humanidade e devem ser socializadas para todos; b) conforme pesquisa de campo realizada pelos alunos, observação in locun do parque visitado, constatou-se que a comunidade goianiense pouco explora e conhece essas práticas e isso impacta na questão social da saúde, pois eles não acessam por que não querem, mas por que são impedidos disso, seja pelas políticas públicas ou pela alta carga de trabalho; c) o material confeccionado é a prova de que o acesso a essas práticas é simples e de baixo custo, portanto, diante de tantos obstáculos à questão da saúde coletiva, no mínimo a dimensão da cultura e lazer podem ser rapidamente garantidos pelo poder público, mas a luta exige que as pessoas tenham consciência desse direito para requerê-lo.

Os alunos envolvidos foram avaliados pelo processo de exploração e do material desenvolvido e por sua síntese na arguição. Ao final da apresentação todos os presentes foram convidados para experimentar o material produzido e conscientizar o máximo de pessoas de seus direitos e das questões que envolvem a saúde.

\section{CONCLUSÃO}

Neste relato de experiência foi possível compreender o caminho metodológico de um processo pedagógico realizado no chão da escola, tratando sobre o conteúdo práticas corporais de aventura e a determinação social da saúde em diálogo com a concepção de saúde coletiva. Nesta experiência didática podemos destacar que ao longo do processo os 23 alunos envolvidos compreenderam a correlação das práticas corporais de aventura (e as demais atividades da cultura corporal) com a saúde coletiva, no viés do determinante social. Pode-se evidenciar que, nas aulas com as práticas corporais de aventura, foram explorados conceitos para além da simplicidade da experimentação e introduzidas categorias complexas, como trabalho e saúde coletiva.

É possível exemplificar com observações feitas em algumas das atividades, como: no slackline, onde alguns alunos afirmaram que nunca tinham visto essa prática; no stand up paddle, onde alunos apontaram que aquilo poderia ser experimentado por muitas outras pessoas; na parede de escalada, onde alunos afirmaram que "[...] talvez mesmo com uma parede dessa na praça pública as pessoas não acessem, pois não têm tempo para isso". De fato, esta última indagação é problemática para uma ação futura, pois existem ações a curto prazo que podem ser resolvidas em intervenções como estas, mas existem outras, referentes ao tempo de trabalho e de lazer, que só serão resolvidas em uma nova organização social.

\section{REFERÊNCIAS}

ANDRADE, L. C.; ANDRADE, J. da S. de; MOURA, S. de A. Pedagogia históricocrítica e educação física: o ensino das práticas corporais de aventura nos anos iniciais. Motrivivência, Florianópolis, v. 32, n. 63, p. 1-15, 2020.

BAGNI, G.; MORÃO, K. G.; VERZANI, R. H.; MACHADO, A. A. Análise de jovens 
no âmbito esportivo: um relato de experiência. Caderno de Educação Física e Esporte, Marechal Cândido Rondon, v. 17, n. 2, p. 119-22, 2019.

BONFIM, I. G.; BASTOS E. N. E.; GÓIS, C. W. de L.; TÓFOLI, L. F. Apoio matricial em saúde mental na atenção primária à saúde: uma análise da produção científica e documental. Interface: Cominicação, Saúde e Educação, Botucatu, v. 17, n. 45, p. 287-300, 2013.

BONFIM, M. R.; COSTA, J. L. R.; MONTEIRO, H. L. Ações da educação física na saúde coletiva brasileira: expectativas versus evidências. Revista Brasileira de Atividade Física e Saúde, Florianópolis, v. 17, n. 3, p. 167-73, 2012.

CAMPOS, F. E.; AGUIAR, R. A. T.; BELISÁRIO, A. S. A formação superior dos profissionais de saúde. In: GIOVANELLA, L.; ESCOREL, S.; LOBATO, L. V. C. NORONHA, J. C.; CARVALHO, A. I. (Org.). Políticas e sistema de saúde no Brasil. 2. ed. Rio de Janeiro: Fiocruz, 2008.

CARVALHO, S. R. Saúde coletiva e promoção à saúde: uma reflexão sobre os temas do sujeito e da mudança. Campinas: DMPS/UNICAMP, 2005.

ESCOBAR, M. O.; TAFFAREL, C. N. Z. A cultura corporal. In: HERMIDA, J. F. (Org.). Educação física: conhecimento e saber escolar. João Pessoa: EDUFPB, 2009. p. $173-80$

FERREIRA, J. K. S.; SILVA, P. C. da C. Práticas corporais de aventura na natureza na educação infantil: um relato de experiência. Caderno de Educação Física e Esporte, Marechal Cândido Rondon, v. 18, n. 3, p. 157-64, 2020.

LIBÂNEO, J. C. Democratização da escola pública: a pedagogia crítico-social dos conteúdos. 13. ed. São Paulo: Loyola, 1985.

MACHADO, M. H.; VIEIRA, A. L. S.; OLIVEIRA, E. Gestão, trabalho e educação em saúde: perspectivas teórico-metodológicas. In: BAPTISTA, T. W. F.; AZEVEDO, C. S.; MACHADO, C. V. (Org.). Políticas, planejamento e gestão em saúde: abordagens e métodos de pesquisa Rio de Janeiro: Fiocruz; 2015. p. 1-2.
MOURA, D. L.; SANTANA, M. A.; XAVIER JUNIOR, J. F.; SILVA, J. C. S.; LIMA, J. M. G.; ARAÚJO, J. G. E.; SOUSA, C. B. Dialogando sobre o ensino da educação física: práticas corporais de aventura na escola. Curitiba: CRV, 2018.

PAIM, J. S.; ALMEIDA FILHO, N. de. Saúde coletiva: uma "nova saúde pública" ou campo aberto a novos paradigmas? Revista Saúde Pública, São Paulo, v. 32 , n. 4, p. 299-316, 1998.

SAVIANI, D. Pedagogia histórico-crítica, quadragésimo ano: novas aproximações. Campinas: Autores Associados, 2019.

SCABAR, T. G.; PELICIONI, A. F.; PELICIONI, M. C. F. Atuação do profissional de Educação Física no Sistema Único de Saúde: uma análise a partir da Política Nacional de Promoção da Saúde e das Diretrizes do Núcleo de Apoio à Saúde da Família - NASF. Journal of the Heath Sciences Institute, São Paulo, v. 30, n. 4, p. 411-8, 2012

SCHWARTZMAN, S. Ciência, universidade e ideologia: a política do conhecimento. Rio de Janeiro: Centro Edelstein, 2008.

SEVERINO, A. J. Metodologia do trabalho científico. São Paulo: Cortez, 2012.

SOARES, C. L.; TAFFAREL, C.; VARJAL, E.; CASTELLANI, L. F.; ESCOBAR, M. O.; BRACHT, V. Metodologia do ensino de educação física. São Paulo: Cortez, 1992

SOUZA, J. P.; LOBO,C. C.; ANJOS, C. L.; PASSARELI, L. F. M. Ansiedade précompetitiva em atletas das categorias de base: relato de experiência em campeonato brasileiro de judô. Caderno de Educação Física e Esporte, Marechal Cândido Rondon, v. 17, n. 2, p. 77-81, 2019.

TAFFAREL, C. N. Z. Pedagogia histórico-crítica e metodologia de ensino crítico-superadora da educação física: Nexos e determinações. Nuances: Estudos sobre Educação, Presidente Prudente, v. 27, n. 1, p. 5-23, 2016.

\section{DEDICATÓRIA}

Dedicamos este relato aos professores que como nós, assumem uma perspectiva crítica na educação básica e não perdem do horizonte a transformação social.

\section{CONFLITO DE INTERESSE}

Os autores do estudo declaram não haver conflito de interesses.

\section{FINANCIAMENTO}

Este estudo não contou com apoio financeiro.

\section{ORCID E E-MAIL DOS AUTORES}

Regina Queiroz Silva ORCID: 0000-0002-5668-1664.

E-mail: rqueirozs@gmail.com

Leonardo Carlos de Andrade (Autor Correspondente) ORCID: 0000-0002-0324-6079.

E-mail: leonardoandradeprof@gmail.com

saac Neves de Lima

ORCID: 0000-0002-2057-2597.

E-mail: issacneves@hotmail.com

Katiane dos Santos Costa

ORCID: 0000-0002-8983-00480.

E-mail: katianesantosc@gmail.com 